\title{
IT gaining ground in Learning
}

\author{
lasmina-Leila Ermalai \\ "Politehnica" University of Timisoara, Faculty of Electronics and Telecommunication, no. 2,
}

Bd. Vasile Pârvan, 300223, Timișoara, Romania

iasmina.ermalai@cm.upt.ro

\author{
Keywords: eLearning, IT, LCMS, Moodle, Semantic Web, Microformats, hCard, Collaborative \\ learning
}

\begin{abstract}
Continuously emerging forms of eLearning like MOOC (Massive Open Online Courses), PLE (Personal Learning Environment) and the use of Semantic Web standards in learning environments, are consistent proof that IT, the Internet, the World Wide Web, Content Management Systems, audio/video lectures, videoconferences, Semantic Web are here to stay, evolve and furthermore, to take control of the learning process, making from it a flexible, viable, profitable and extensively used solution for delivering knowledge. In this general context, the present paper offers an eLearning state-of-the-art and an overview of the trends and technologies proposed, developed and implemented in a particular eLearning environment, over the last years, as part of a postdoctoral research program. The mentioned environment was the Moodle portal used at the "Politehnica" University of Timisoara, the implemented standards were the hCard and hCalendar microformats and the proposed model was one of collective learning through question answering.
\end{abstract}

\section{Introduction}

The "digital natives" or the "n-gen" (n generation) are the new generations of learners brought up with the Internet and an unrestrained access to information; they absorb information simultaneously from multiple sources, through images, video or text and they prefer random and on-demand access to educational materials, as they are continuously connected to web tools, being in the same time providers and consumers of media material. [1;2] Nowadays one can say that we aspire to a "learning culture", rather than a "knowledge era", in a time when people are continuously surrounded and absorbed by educational experiences [3].

The activity of teaching in an electronic classroom (cyberspace) implies, according to Palloff and Pratt [3] more than taking the models of traditional teaching and transferring them into an online environment; it involves changes in the way education is distributed in general.

Khan's collaboration with students, instructors, administrators and technical staff from all over the world, all part of an academic or corporate eLearning environment, made him realise that the eLearning framework is made out of eight key dimensions: pedagogical, technological, interface design, evaluation, management, resources support, ethical and institutional. Based on these dimensions he created a figure, known in literature as "eLearning framework" [4].

The attempts made over the years to revolutionize education with innovative technologies taught us, according to Clarke [5], an important lesson: for technology to improve education, it must "match" the students' lives and not vice versa. This conclusion led to the birth of eLearning.

Over the years, the degree of technology integration in learning activities grew and evolved so as to accommodate with individualized needs of students and also to compensate to some extent the drawbacks generated by the lack of sufficient face-to-face meetings with the teachers. From the first methods used in distance learning - letters - to nowadays MOOCs, PLEs, or immersive learning, the road had been long and it included a wide variety of tools and methods, spanning over three major types of pedagogy: cognitive-behaviourism, constructivism and connectivism [6]. The abundance of information on the World Wide Web and the continuously evolving methods and tools used to deliver data, led to change of the pedagogy models, needed in order to adapt traditional teaching methods to the "pedagogy of abundance" [7]. 
Massive Open Online Courses (MOOCs), emerged in 2008 [8], a relatively new term in the "elearning landscape", based on connectivism, proved to be time-consuming at an early stage and in the case of "massive courses". Later on, the concept was embraced by some of the most famous worldwide universities, like University of Stanford, where a course offered in 2011 attracted 160,000 registered users from 190 countries, 20,000 of them successfully finishing the course (without receiving grades or credit) [9].

PLEs (Personal Learning Environments) are learner-centric systems that consist of "tools, communities, and services" [10] that "allow students to gain competence or knowledge regardless of whether the tool enables interaction with another student about a class project or going online to find examples or suggestions on how to approach a project." [11] PLEs could heavily rely on the exponential potential that Semantic Web has to offer [12].

This paper presents an overview of worldwide eLearning trends and also of the research activities directed towards enriching the eLearning experience of students, activities carried out during a postdoctoral program. Section 2 is structured in three parts and, presenting the following: a state-ofthe-art in collaborative learning, in the integration of Semantic Web in learning, and in eLearning technologies used in teaching math and science. The next section is structured in two subsections, the first one presents the process of implementing microformats into a particular learning management system, Moodle, used at "Politehnica" University of Timisoara (UPT), while the second one briefly presents a Q\&A model proposed in collaboration with the Institute of Applied Sciences from the University of Girona, Spain. Last, there are the discussions on the directions followed so far and also a presentation of the possible future perspectives.

The purpose was to offer an insight of the present tendencies and technologies used in eLearning, needed as a starting point and also as a standard used to compare some actual steps taken in a particular learning environment. The perspective was the one of an eLearning researcher and also a teaching assistant who has been seeking to use various information technologies to enhance the students' learning process. The research resources consisted mainly of papers on e-Learning, MOOCs, PLEs, Semantic Web in education, found through the use of Scholar Google.

\section{eLearning trends}

On one hand, there is the collaborative model of learning, which over the years has proven its efficiency, in traditional or non-traditional learning environments, and on the other hand there is the increasing use of technology in learning. Thus, the use various tools to provide environments or means to increase collaboration between students appeared as the normal next thing. Naturally, the desired situation would be the one in which intelligent applications could learn the behaviour of the user, in order to better supervise and enhance interaction with other users or software.

Collaborative Learning - State-of-the-art. One agrees with Mitra's claim that "education is a self-organising system, where learning is an emergent phenomenon" [13]. Recent surveys show that many people turn to social networks when they need information or seek answers to their subjective questions. The main enablers are trust (Q\&A sites provide answers from strangers, while social networks provide answers from people you know), response time (social networks are faster than Q\&A sites), effort, personalization, and social awareness, as detailed in [14]. People often resort to social networks as they find it easier to formulate a full question, rather than to recurrently try to find the right keywords, moreover when answers come from network friends, which have a certain degree of trust and expertise, usually known by the questioner. Each question is a good starting point for building knowledge, as "collaborative knowledge is a cyclical process with no beginning or end" [15].

The American psychologist William Glasser states in his book "Control Theory in the Classroom" [16] that students remember more information when they are actively engaged in learning; learning is a social act and we learn more by collaborating, communicating within a group; a parallel can be drawn between traditional and online education, following Glasser's trial data which reveal that: we remember $10 \%$ of what we read, $20 \%$ of what we hear, $30 \%$ of what we see, $50 \%$ of what we hear and see, $70 \%$ of what we talk with others, $80 \%$ of what we experiment and $95 \%$ of what we teach others. 
There is an interesting social approach called Self Organized Learning Environments (SOLE) by the work of Mitra and Dangwal, empowered by online social networks, mobile applications, and social currencies, and leaning on Social Constructivism for computer supported collaborative learning (CSCL). The Mitra's hole-in-the-wall experiments [17] showed that groups of children, given shared digital resources, can learn to use computers and the Internet and go on to learn almost anything that they have an interest in, on their own. They do not seem to require adult supervision. Their future work showed that groups of children with access to computer and related technology were capable of successfully answering examinations without traditional schooling.

In order to apply models of instruction which would have their roots in this perspective it is important to know the following bases: individuals create meaning through their interactions with each other and with the objects which are in their context; learning is a social process and it happens when people are engaged in social activities. It isn't a passive development of behaviours that are shaped by external forces [18].

The 'Zone of Proximal Development' is a Vygotskian notion. It is defined as "the distance between the actual developmental level as determined by independent problem solving and the level of potential development as determined through problem solving under adult guidance or in collaboration with more capable peers"[19]. It has significant implications for peer collaboration.

The main method in which CSCL can get a degree of structure and an infusion of intelligent learning assistance is through the use of scripting.

Scripting in education is regarded as a method designed externally by others, used for structuring collaborative learning, with the aim of assisting group interaction that promotes learning [20]. Collaborative learning scripting usually follows a guide-and-constrain strategy to direct the actions of the learner, based on the premises that specific patterns of interaction are effective for learning. The three main advantages offered by this approach are the following: offloading tasks generated by the management of collaborative learning, guiding the learner into productive interactions, and communicating instructional design [21]. One of the biggest challenges for scripting, as presented by Dillenbourg and Tchounikine [22], was to establish the right degree of coercion, as "too rigid scripts would spoil the richness of collaborative interactions; too flexible scripts would fail to induce the targeted interactions".

Liu and Lin presented an algorithm which used individual Learning Agents (used to track the progress of each learner and to update the Learner Experience Vector) and also Group Agents, for "automatically grouping homogeneous learners and dynamically regrouping learners when they change their learning behaviour" [23].

Haake and Pfister published a study in 2010, which revealed the fact that scripted net-based learning collaboration was neither generally advantageous, nor disadvantageous in the case of university students taking a one-semester operating systems course [24].

Other studies revealed the fact that intelligent and adaptive collaborative learning systems were hard to implement and use on a large scale as they were research prototypes, strongly domainspecific and there were no large scale available confirmations that this approach had been affective in increasing the learning outcomes. Still, more current research revealed the fact that an adaptive support mechanism could be implemented into open source systems and could positively affect student learning [25].

Semantic Web in learning environments. The abundance of information mentioned in the introduction section led to significant time and effort invested in processing the returned data in order to find the needed information. Consequently, in the last years, considerable attention and effort have been invested in finding methods of intelligently publishing information on the WWW, by adding defined meaning, creating a structure, so that intelligent applications/software could easily collect information from various sources, process it, or exchange data with other application. Even if some of these processes are not visible to the user, they all have the same goal: to enhance the user experience. Due to the volume of web data and of applications used nowadays, a complete reconstruction of the World Wide Web in not a feasible solution. The remaining alternative is to 
extend the functionalities of the existing applications, by adding a semantic layer to the information. Sir Timothy Berners-Lee, the parent of the WWW, called this layer the Semantic Web and envisioned it as an extension of the current web in which information receives a well-defined meaning, enhancing thus the communication between humans and machines [26].

The impact that the use of Semantic Web tools based on ontologies would have on learning is huge, but nevertheless, the initiatives made in this direction are rather isolated, since conveying on a joint standard and completely redesigning existing solutions proved to be more than challenging. That is the main reason why the most common steps taken towards semantics were the one that implied fewer changes in existing online environments, like using RDF or microformats.

Nevertheless, projects like the one described in [27] provide evidence of semantic web learning systems based on RDF/XML, OWL and DBPedia Knowledge Base, producing learning data that could be shared and reused in other learning systems.

eLearning in math and science. When extending ones perspectives to also include pre-university students, the e-Learning possibilities grow considerably. Rojano [28] stated that students could learn mote mathematics and on a deeper level with the use of technology, while Moses and Cobb [29] considered technology as means of organizing thoughts, the most effective way of assisting students in learning, and an inevitable consequence of changing times.

The official position of the National Council of Teachers of Mathematics (NCTM) http://www.nctm.org - regarding the role of technology in the teaching and learning of mathematics was the following: "Technology is an essential tool for learning mathematics in the 21 st century, and all schools must ensure that all their students have access to technology. Effective teachers maximize the potential of technology to develop students' understanding, stimulate their interest, and increase their proficiency in mathematics. When technology is used strategically, it can provide access to mathematics for all students." NCTM considers that "calculators and other technological tools, such as computer algebra systems, interactive geometry software, applets, spreadsheets, and interactive presentation devices, are vital components of a high-quality mathematics education."[30] They offer a variety of resources, organized in various categories: Elementary, Middle School and High School; Resources by theme; Teaching tips; Family corner and so on. Also, they provide online sites and portals that offer lessons and activities for students, like: Illuminations (http://illuminations.nctm.org/), and FigureThis (http://www.figurethis.org/index.html),

The teachers' attitude and belief towards using eLearning when teaching mathematics, was also a very important aspect which had to be taken into consideration. Most of today's Math teachers have learned in a traditional way of face-to-face meetings, and paper and pen. They may be reluctant when it comes to learning new technologies, to revising their learning material as to adapt it to these technologies and to completely change the way they have been delivering knowledge so far. Thus the first step would be, in many real life examples, to educate the educators.

PCK, a term coined by Schulman in 1986, stands for Pedagogical Content Knowledge, "which goes beyond knowledge of a subject matter per se to the dimension of subject matter knowledge for teaching" [31], including from behalf of the teacher the understanding of what makes learning easy or difficult and the most useful methods for making a subject comprehensible by students. It is actually knowledge of the matter and knowledge of how to teach it. Extending the use of PCK with technology, in eLearning environments, led to the term TPCK - Technology Pedagogical Content Knowledge - which mainly means "teaching with technology" [32].

Methods used so far in mathematics courses, described in the book "Teaching Mathematics Online: Emergent Technologies and Methodologies" [33], vary from screencasts of live lectures and of short snippets of theory or examples, to general e-Learning tools like LMSs, wikis and speaking avatars. WIRIS, GeoGebra, SAGE and Wolfram Alpha are other tools used for teaching mathematics.

Cady et al. [34] present various e-Learning environments used by middle school math and science teachers. For the mathematical courses, they use Blackboard for asynchronous activities and Centra for the synchronous activities, providing voice interactions with participants. Other tools were Geometer's Sketchpad and Notetaker. For the science courses, they used Blackboard and WordPress. 
The Department of Mathematics for Science and Technology of the University of Minho in Portugal reported that in 2010 the use of Maple T.A. - an e-Learning platform specially designed for teaching Mathematics - helped students achieve better results on the course of Calculus [35].

\section{Microformats in Moodle. A model for collaborative learning through Q\&A}

This section presents two different approaches of eLearning, undertaken at the Multimedia Centre from the "Politehnica" University of Timisoara.

Microformats in particular Moodle environment. To enhance the user experience, we have developed and integrated into Moodle a module that allows publishing users' information by using the hCard class. The process was not difficult, nor time consuming, and the main advantage was that it did not interfere with the Moodle core. Moreover, the decision block ran on the user's computer, meaning that this process din not overload the server. The user only needed to install a plug-in in the used browser (there are different plugging for different browsers ${ }^{1}$, for example Operator for Mozilla, Oomph for Internet Explorer, Michromeformats for Chrome) and the information published using microformats was detected by the plug-in and various methods of processing were offered, as seen in the Fig.1.

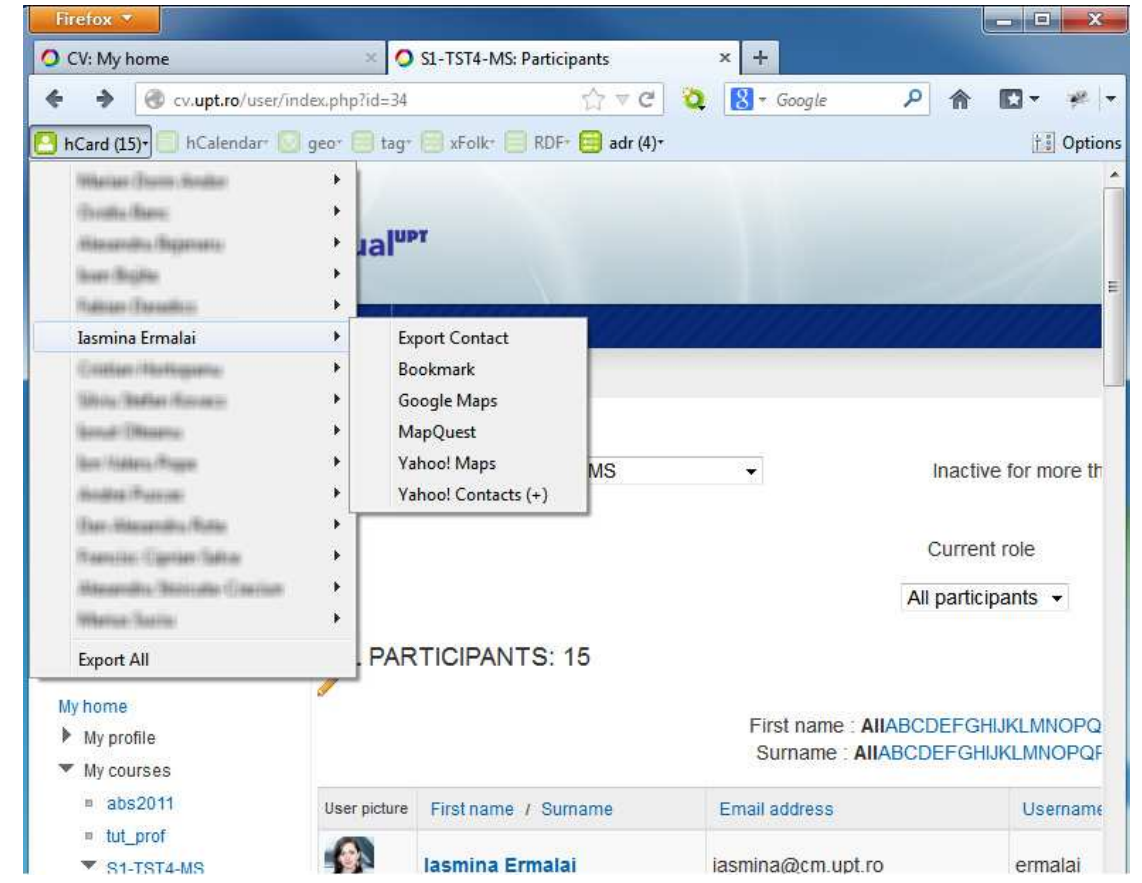

Fig. 1: Operator detecting data published with hCard

There are two main advantages of using microformats. The first and visible one is offering a new method of handling contact information published in Moodle. The second one, invisible to the user, is the advantage of improving search results presentation. For example, Google relies on microformats for creating a visually attractive method of displaying search result - the Rich Snippets [36]. A detailed description of the development and integration were published in various papers, amongst which the latest is waiting for evaluation [37].

A model for Q\&A-based collaborative learning. The current situation shows that most intelligent collaborative learning relies on learner agents or multiple-agents to create learner communities and to guide learners through the learning process. More complex models appeared at that time too difficult to implement on a larger scale and to adapt to various learning systems. This is the general context which allows us to propose a simple Q\&A based system, designed to increase knowledge gathering in a collaborative environment. Simulations compared two models: the classic model, where students ask and teachers answer, and proposed one, where students ask and peers answer.

\footnotetext{
${ }^{1}$ http://microformats.org/wiki/browsers
} 
Results showed that the increase in knowledge was more significant in the latter case, leading to the conclusion that peer learning could prove to be a viable solution that would increase knowledge and interest of students, and also unload the teacher's tasks, as he would only be a supervisor of the process. Premises, simulations, results and conclusions were detailed in the paper entitled "Analysis of the benefits of collective learning through questions answering", published in 2012 [38].

\section{Discussions and further perspective}

As it can be observed by performing a simple search for learning material on the web, the returned results are numerous and diverse. The field of eLearning has progressively extended its traditional association with distance learning, to offer additional means of gathering knowledge in any field and at any educational level. Researchers and teachers worldwide are seeking ways to more efficiently offer courses to a wider audience, experience that could become collective and personalised in the same time, and moreover, assisted by intelligent agents. Indeed informational technologies are taking over learning. This will be the future of learning. To some extent it already is the present. However, one should always consider the fact that using technology to deliver knowledge can be a powerful tool, but "a teacher's decision to incorporate digital technologies should only occur in the context of content and pedagogy" [39].

In this general context and evolution of things, the "Politehnica" University of Timisoara has also made some notable steps towards developing, integrating and using various informational technologies in the educational process, first with the distance learning students, and presently with students enrolled at every university level.

The most important milestone was the migration of the online activities towards Moodle, followed, amongst others, by the integration of the lower-case Semantic Web, microformats, into the learning system, thus offering users a supplementary tool that could ease the administrative workload of learning. There is much room to develop when it comes to information processing techniques and the short term plans are directed towards using RDF for publishing data available through the learning system.

Recently, online collaborative learning also captured our interest, leading to the proposal of a Q\&A model. The fact that simulations revealed a considerable increase in knowledge in the case of peer-to-peer question answering generated the need for a proof-of-concept. This will be the next step and it will require the development of a Q\&A collaborative module for Moodle, followed by its testing during one semester, with at least one subject.

Regarding the undertaken eLearning initiatives, the younger the students, the more receptive they proved to be. This was also the case of the tutors involved in delivering knowledge through online methods. One has to always consider providing online and/or face-to-face tutorials when it comes to using new technologies, for both students, as well as tutors.

\section{Acknowledgment}

This paper was supported by the project "Development and support of multidisciplinary postdoctoral programmes in major technical areas of national strategy of Research - Development Innovation" 4D-POSTDOC, contract no. POSDRU/89/1.5/S/52603, project co-funded by the European Social Fund through Sectoral Operational Programme Human Resources Development 2007-2013.

\section{References}

[1] D. Tapscott, Growing Up Digital: The Rise of the Net Generation, McGraw-Hill, New York.

[2] AppleEducation, Digital Tools for Digital Students.

[3] R. Palloff, and K. Pratt, Lessons from the Cyberspace Classroom, 17th Annual Conference on Distance Teaching and Learning, Madison, Wisconsin, 2001. 
[4] B. Khan, Framework for E-Learning.

[5] D.J. Clarke, E-Learning: Big Bang or Steady Evolution. Learning Technologies (2002).

[6] T. Anderson, and J. Dron, Three generations of distance education pedagogy. The International Review of Research in Open and Distance Learning, Special Issue - Connectivism: Design and Delivery of Social Networked Learning 12 (2011) 80-97.

[7] M. Weller, A pedagogy of abundance. Spanish Journal of Pedagogy 249 223-236.

[8] A. Fini, The Technological Dimension of a Massive Open Online Course: The Case of the CCK08 Course Tools. The International Review of Research in Open and Distance Learning 10 (2009).

[9] O. Rodriguez, MOOCs and the AI-Stanford like Courses: Two Successful and Distinct Course Formats for Massive Open Online Courses. European Journal of Open, Distance and eLearning (2012).

[10] EDUCAUSE Learning Initiative (ELI), 7 Things You Should Know About Personal Learning Environments. (2009).

[11] N. Dabbagha, and A. Kitsantasb, Personal Learning Environments, social media, and selfregulated learning: A natural formula for connecting formal and informal learning. The Internet and Higher Education 15 (2012) 3-8.

[12] R. Tozman, Learning in the Semantic Web, eLearn Magazine, 2012.

[13] S. Mitra, and M. Dangwal, Limits to self-organising systems of learning - the Kalikuppam experiment. British Journal of Educational Technology 41 (2010) 672-688.

[14] M. Ringel Morris, J. Teevan, and K. Panovich, What do people ask their social networks, and why?: a survey study of status message q\&a behavior, Proceedings of the 28th international conference on Human factors in computing systems, ACM, Atlanta, Georgia, USA, 2010.

[15] G. Stahl, Building Collaborative Knowing, What We Know About CSCL, Springer Netherlands, 2004, pp. 53-85.

[16] W. Glasser, Control Theory in the Classroom, Perennial Library, New York, 1986.

[17] S. Mitra, Minimally invasive education: a progress report on the "hole-in-the-wall" experiments. British Journal of Educational Technology 34 (2003) 367-371.

[18] M. McMahon, Social Constructivism and the World Wide Web - A Paradigm for Learning, What works and why : reflections on learning with technology : ASCILITE, Perth, Australia, 1997.

[19] L.S. Vygotsky, The collected works of L.S. Vygotsky: Vol. I Problems of general psychology, New York: Plenum Press, 1987.

[20] A. King, Chapter 2 - Scripting Collaborative Learning Process: A Cognitive Perspective, Scripting Computer-Supported Collaborative Learning - Cognitive, Computational and Educational Perspectives, Springer Science+Business Media, LLC, 2007.

[21] D.D. Suthers, Chapter 11 - Discussions. Roles of Computational Scripts, Scripting ComputerSupported Collaborative Learning - Cognitive, Computational and Educational Perspectives, Springer Science+Business Media, LLC, 2007, pp. 177-185.

[22] P. Dillenbourg, and P. Tchounikine, Flexibility in macro-scripts for computer-supported collaborative learning. Journal of Computer Assisted Learning 23 (2007) 1-13.

[23] F. Liu, and Z. Lin, Building a Community-Based Collaborative Learning System Using MultiAgent, Ieee Computer Soc, Los Alamitos, 2009.

[24] J.M. Haake, and H.R. Pfister, Scripting a distance-learning university course: Do students benefit from net-based scripted collaboration? International Journal of Computer-Supported Collaborative Learning 5 (2010) 191-210.

[25] A. Karakostas, and S. Demetriadis, Enhancing collaborative learning through dynamic forms of support: the impact of an adaptive domain-specific support strategy. Journal of Computer Assisted Learning 27 (2011) 243-258.

[26] T. Berners-Lee, J. Hendler, and O. Lassila, The Semantic Web, Scientific American, New York, 2001. 
[27] J. Narimisaei, B. Shadgar, and B. Shadgar, Knowledge Construction and Representation in ELearning using Semantic Web Techniques. International Journal of Computer Applications 43 (2012) 23-26.

[28] T. Rojano, The role of problems and problem solving in the development of algebra. in: C.K. Nadine Bednarz, Lesley Lee, (Ed.), Approaches to algebra: Perspectives for research and teaching, Dordrecht ; Boston : Kluwer Academic Publishers, 1996.

[29] R.P. Moses, and C.E. Cobb, Radical Equations: Math Literacy and Civil Rights, 2001.

[30] NCTM, The Role of Technology in the Teaching and Learning of Mathematics, National Council of Teachers of Mathematics, 2008.

[31] L.S. Shulman, Those Who Understand: Knowledge Growth in Teaching. Educational Researcher, 15 (1986) 4-14.

[32] M.L. Niess, Preparing teachers to teach science and mathematics with technology: Developing a technology pedagogical content knowledge. Teaching and Teacher Education 21 (2005) 509523.

[33] H. Cuypers, Book Review of Teaching Mathematics Online: Emergent Technologies and Methodologies, Universities and Knowledge Society Journal (RUSC), 2012.

[34] J. A. Cady, Mehmet Aydeniz, and K.T. Rearden, E-Learning Environments for Math and Science Teachers. Journal of Curriculum and Instruction (JoCI) 5 (2011) 17-33.

[35] R.M. S. Pereira, I. Brito, G. Q. Machado, T. Malheiro, E. Vaz, M. Flores, J. Figueiredo, P. Pereira, and A. Jesus, New e-learning objects for the Mathematics courses from Engineering degrees: Design and Implementation of Question Banks in Maple T.A. using LaTeX. International Journal of Education and Information Technologies 4 (2010).

[36] T. Steiner, R. Troncy, and M. Hausenblas, How Google is using Linked Data Today and Vision For Tomorrow, Linked Data in the Future Internet, Ghent, Belgium, 2010.

[37] I. Ermalai, B. Dragulescu, A. Ternauciuc, and R. Vasiu, Building a Module for Inserting Microformats into Moodle, (unpublished work) 2012.

[38] I. Ermalai, J. L. de la Rosa, and A. Moreno, Analysis of the benefits of collective learning through question answering, 4th International Conference on Computer Supported Education CSEDU2012, Porto, Portugal, 2012.

[39] E. O. Crawford, and M.M. Kirby, Fostering students' global awareness: Technology application in social studies teaching and learning. Fostering students' global awareness: Technology application in social studies teaching and learning 2 (2008) 56-73. 